\title{
How companies succeed and fail to succeed with the implementation of intelligence systems
}

Most papers in this issue deal with different sides of technological systems and managerial practices used for intelligence work in private organizations. Empirical data from a number of countries and companies are gathered to illustrate how companies work and fail to work with business intelligence and competitive intelligence in organizations.

The paper by Rezaie, Mirabedini and Abtahi entitled "Identifying key effective factors on the implementation process of business intelligence in the banking industry of Iran" identifies key effective factors on the implementation process of business intelligence. Thirty-nine factors were identified and classified in nine main groups, including organizational, human, data quality, environmental, system ability, strategic, service quality, technical infrastructure, and managerial factors.

The paper by Bisson and Gurpinar entitled "A Bayesian approach to developing a strategic early warning system for the French milk market" suggests a new strategic early warning system for companies and public organizations to better anticipate market changes and make more robust decisions.

The paper by Al Rashdi and Nair entitled "A business intelligence framework for Sultan Qaboos University: A case study in the Middle East" aims to build a customized business intelligence (BI) framework for Sultan Qaboos University (SQU). A prototype is tested with good results.

The paper by Søilen, Tontini, Aagerup and Andersson entitled "The perception of useful information derived from Twitter: A survey of professionals" is a survey of professionals about the value of the information or intelligence on Twitter. It shows that Twitter is perceived as a service for useful information but not for the reason one may expect, not because the content of the tweets gives valuable information, but because of what can be derived and extracted from the information that is being tweeted and not tweeted.

The paper by Calof, Richards and Santilli entitled "Insight through open intelligence" is an opinion piece that gives suggestions of how to broaden the CI field with the help of open innovation.

As always, we would above all like to thank the authors for their contributions to this issue of JISIB. Thanks to Dr. Allison Perrigo for reviewing English grammar and helping with layout design for all articles and to the Swedish Research Council for continuous financial support.

On behalf of the Editorial Board,

Sincerely Yours,

$$
\text { Kriñ 1. Nin }
$$

Prof. Dr. Klaus Solberg Søilen

Halmstad University, Sweden

Editor-in-chief 